\title{
Pengaruh Karakteristik Individu dan Lingkungan Kerja Terhadap Kinerja Karyawan PT. MNS (Multi Nabati Sulawesi) Bitung
}

\author{
Mutiarawati Saliding \\ Willy A. Areros \\ Wehelmina Rumawas \\ Jurusan Ilmu Administrasi Bisnis, Program Studi Administrasi Bisnis \\ Fakultas Ilmu Sosial dan Politik. Universitas Sam Ratulangi \\ Mutiarawatisaliding17@gmail.com
}

\begin{abstract}
The progress of the company was not the eye of the eye located on how much profit they were by, but it is also in human resources to form in a company to be established to be paranoid to be well eployess well based on justice or company policy considering humanity values, work achievement, education, and work experience.This research is aiming to know the Individual Characteristics and Work Environment to Employee Performance. Research that located at PT. Multi Nabati Sulawesi Bitung. The sample taken was 112 people from a total 450 employees in the company. In this study are using simple statistics with a simple regression with the SPSS version 23.00 to test the significant connection between variables and to measure the glory of the influence that occurs on variation of Individual Characteristics and Work Environment to Employee Performance. Based on the calculations of using the SPSS 23.00 software device that's a variable Individual Characteristics of affects the employee performance variables which show that Work Environment received is not in accordance with the expectation and desires of employees, so that there is a coplaint for every employee in the company
\end{abstract}

\section{Keywords: Individual characteristics, Work Enivornment, Employee Performance}

\section{Pendahuluan}

Sumber daya manusia merupakan asset paling berharga yang di miliki oleh instansi, perusahaan atau organisasi, keberadaan sangat menentukan terhadap mobilitas perusahaan. Oleh karena itu, banyak perusahaan selalu berusaha meningkatkan kualitas sumber daya agar aktivitas kerjannya dapat dijalankan dengan maksimal.

Schermerhorn menyatakan bahwa sumber daya manusia adalah orang, individu-individu, dan kelompok-kelompok yang membantu organisasi menghasilkan barang-barang atau jasa-jasa. (Rumawas Wehelmina, 2018)

Begitupula sebaliknya, karyawan dengan karakteristik buruk akan memperhambat perusahaan beroperasi dan berkembang. Berdasarkan hal tersebut sudah di pastikan bahwa perusahaan mempunyai kriteria tertentu pada karyawan yang mereka pekerjakan sehinggah sesuai dengan kebutuhan perusahaan.

Karakteristik individu yang heterogen dapat menciptakan setiap individu yang 
berbeda kontribusi kenerja pada perusahaan. Karyawan memiliki karakteristik baik dapat menjadikan karyawan tersebut lebih muda mengerjakan pekerjaannya, agar kinerja yang di hasilkan menjadi optimal dan sangat berpengaruh baik bagi perusahaan.

Kinerja karyawan adalah apa yang di lakukan dan tidak di lakukan oleh karyawan. Kinerja karyawan mempengaruhi keberlangsungan perusahaan tersebut dalam mencapai tujuan perusahaan. Kinerja karyawan yang baik dapat memberikan keuntungan bagi perusahaan, sedangkan kinerja yang buruk dapat menghasilkan kerugian bagi perusahaan.

Menurut Peoni (2014), manajemen sumber daya manusia di akui sebagai suatu isu global dan integral dari daya saing diera globalisasi karena tidak dapat dipungkiri bahwa segala masalah yang muncul dalam perkembangan dan persaingan pelayanan public maupun bisnis yang berasal dari manusia dan hanya dapat di kelola dan di selesaiakan oleh manusia itu sendiri. Oleh karena itu muncul konsep penting yang di akui sebagai kunci keunggulan di bidang sumber daya manusia (SDM) yang melalui the right people in the right place at the right time.

Manusia selalu berperan aktif dan dominan dalam setiap kegiatan organisasi publik dan bisnis, karena manusia menjadi perencanaan, pelaku dan penentu terwujudnya tujuan organisasi publik dan bisnis. Tujuan tersebut tidak akan memberikan manfaat bagi organisasi jika tidak ada peran aktif dari kinerja karyawan.

Mengatur karyawan memiliki tingkat kesulitan dan kompleksitas tertentu, karena karyawan mempunyai pikiran, perasaan, status, keinginan, dan latar belakang yang heterogen, yang membedakan antara satu dengan yang lain (khas).

Pendekatan sumber daya manusia berarti organisasi harus mampu menciptakan kepuasan dan rasa aman dalam bekerja (quality of work life) di lingkungan kerjanya sumber daya manusia menjadi kompetitif. Semua perusahaan, karyawan/ pekerja memerlukan sumber daya manusia yang terbuka dalam komunikasi dan tanggung jawab serta batas-batas wewenang masing-masing.

Manajemen sumber daya manusia sangat memperhatikan proses kinerja karyawan sesuai dengan beban pekerjaan dalam organisasi yang menciptakan lingkungan harmoni. Hubungan manajemen organisasi dengan kinerja karyawan dan hubungan antara devisi/bagian di suatu organisasi dapat memberikan dampak yang nyaman dan sehat di antara sesama karyawan, karena karyawan merupakan modal penting (human capital) bagi perusahaan. 
Permasalahan yang ada pada PT. MNS (Multi Nabati Sulawesi) Bitung adalah sebagian karyawan yang bekerja tidak memiliki sikap yang baik, hal ini di sebabkan karena para karyawan tidak mematuhi peraturan yang ada seperti tidak tepat waktu jam pulang kerja dan sementara jam kerja keluar tanpa ada keterangan apapun dan balik ketempat kerja itupun kurang lebih 2-3 jam bahkan sudah tidak lagi melaksanakan tugas dan tanggung jawab dan sementara melaksanakan pekerjaan dengan keadaan mabuk.

Uraian di atas telah menjelaskan bagaimana pentingnya karakteristik individu dan lingkungan kerja terhadap kinerja karyawan pada perusahaan, uraian di atas menunjukan perusahaan harus mengkondisikan keadaan lingkungan kerja perusahaan sesuai dengan karakteristik individu karyawan demi tercapainya tujuan perusahaan secara efektif kinerja karyawan dapat meningkat.

Berdasarkan uraian tersebut, penelitian tertarik untuk menganalisis dan mengetahui hasilnya melalui penelitian pada "Pengaruh Karakteristik Individu dan Lingkungan Kerja Terhadap Kinerja Karyawan PT MNS(Multi Nabati Sulawesi) Bitung”.

\section{Sumber Daya Manusia}

Sumber daya manusia merupakan asset paling berharga yang di miliki oleh instansi, perusahaan atau organisasi, keberadaan sangat menentukan terhadap mobilitas perusahaan. Oleh karena itu, banyak perusahaan selalu berusaha meningkatkan kualitas sumber daya agar aktivitas kerjannya dapat dijalankan dengan maksimal.

Schermerhorn menyatakan dalam Rumawas Wehelmina 2018 bahwa sumber daya manusia adalah orang, individuindividu, dan kelompok-kelompok yang membantu organisasi menghasilkan barang-barang atau jasa-jasa.

\section{Karakteristik Individu}

Karakteristik individu menurut Robbins, (1996:78-100) dalam Peoni 2014 mengemukakan bahwa variabel di tingkat individu meliputi karakteristik biografis, kemampuan, kepribadian, dan pembelajaran. Sedangkan karakteristik biologis meliputi: usia, jenis kelamin, status perkawinan, banyaknya tanggungan dan masa kerja dengan suatu organisasi dari karya itu sendiri.

Menurut Nimran dalam Kurniawati (2007:17-18) dalam Abdul Rahman 2013 Indikator karakteristik individu meliputi sebagai berikut: 
1. Kepribadian

Kepribadian adalah seperangkat karakteristik yang relatif mantap, kecenderungan dan perangai yang sebagian besar di bentuk oleh faktor keturunan dan oleh faktor-faktor social, kebudayaan, dan lingkungan.

2. Sikap

Sikap mempunyai arti penting dalam perilaku, jika anggota yang sikapnya negatif terhadap pekerjaan atau tugasnya cenderung menghasilkan prestasi kerja yang tidak baik. Sebaliknya anggota yang memiliki sikap positif terhadap tugas/pekerjaannya cenderung menghasilkan prestasi kerja (kinerja) yang lebih baik.

3. Kemampuan

Kemampuan adalah suatu kepastian yang di miliki seseorang untuk melaksanakan berbagai kegiatan dalam suatu pekerjaan.

\section{Lingkungan Kerja}

Lingkungan kerja adalah jumlah hubungan timbal balik yang ada dalam karyawan dan lingkungan di mana mereka bekerja (Samson et al, 2015 dalam Ratna Handayati 2016). Lingkungan kerja tentunya mempunyai pengaruh yang tidak kecil terhadap kinerja karyawan yang menjalankan operasi perusahaan, sehinggah baik secara langsung maupun tidak langsung akan tetap mempengaruhi tingkat produktifitas perusahaan.

\section{Indikator Lingkungan Kerja}

Samson et al. (2015) dalam Ratna Handayati (2016) menyatakan ada dua indikator dari lingkungan kerja yaitu:

1. Lingkungan fisik

Lingkungan fisik meliputi komponen lingkungan kerja nyata yang terdiri tat ruang dan fungsi dari lingkungan. Samson et al. (2015) dalam Ratna Handayanti 2016 mengklasifikasikan lingkungan fisik menjadi 3 kategori, yaitu:
a) Furnitur
b) Pencahayaan dan ventilasi
c) Kebisingan

2. Lingkungan psikososial

Faktor lingkungan psikososial di anggap salah satuisu paling penting dalam masa depan dan masyarakat kontemporer. Samson et al (2015) dalam Ratna Handayati 2016 mengklasifikasi lingkungan psikososial menjadi 3 kategori, yaitu:
a) Dukungan Atasan
b) Peran Harmoni
c) Kualitas Kepemimpinan

\section{Kinerja Karyawan}

Menurut Mathis dan Jakson (2002) dalam Peoni 2014 kinerja karyawan adalah 
yang mempengaruhi seberapa banyak mereka memberikan kontribusi kepada organisasi. Kinerja merupakan hal yang sangat penting dalam suatu perusahaan untuk mencapai tujuannya.

Kinerja dapat berjalan baik apabila karyawan men-dapatkan gaji sesuai harapan, mendapatkan pelatihan dan pengembangan, lingkungan kerja yang kondusif, mendapatkan per-lakuan yang sama, penjabatan karyawan sesuai keahliannya serta mendapatkan bantuan perencanaan karir, serta terdapat umpan balik dari perusahaan.

\section{Indikator Kinerja Karyawan}

Indikator kinerja karyawan adalah:

1. Kualitas

Kualitas kerja adalah seberapa baik seorang karyawan mengerjakan apa yang seharusnya di kerjakan.

2. Kuantitas

Kuantitas kerja adalah seberapa lama seorang pegawai bekerja dalam suatu harinya. Kuantitas kerja ini dapat dilihat dari kecepatan kerja setiap pegawai itu masing-masing.

3. Pelaksanaan Tugas

Pelaksanaan tugas adalah seberapa jauh karyawan mampu melakukan pekerjaannya dengan akurat atau tidak ada kesalahan.

\section{Tanggung Jawab}

Tanggung jawab terhadap pekerjaan adalah kesabaran akan kewajiban karyawan untuk melaksanakan pekerjaan yang di berikan perusahaan.

\section{Metode Penelitian}

Penelitian yang digunakan dalam penelitian ini yaitu penelitian kuantitatif., Pendekatan Yang digunakan adalah Pendekatan Survey. Populasi dalam penelitian ini yaitu Karyawan Tetap PT. Multi Nabati Sulawesi yang terletak di Bitung yang jumlahnya 450 Karyawan. Untuk menentukan sampel digunakan rumus Slovin, sehingga diperoleh sampel sebanyak 112 orang. Teknik yang digunakan yaitu kuesioner, Observasi dan studi kepustakaan. Instrumen penelitian yang digunakan yaitu skala likert dan untuk menguji instrument penelitian menggunakan uji validitas, uji reliabilitas dan analisis koefisiensi determinasi (R2). Analisis data yang digunakan yaitu analisis regresi linear berganda.

\section{Hasil Penelitian}

\section{Analisis Uji Instrumen Penelitian}

a. Uji Validitas

Semua pernyataan yang terdapat dalam variabel Karakteristik Individu (X1) variabel Lingkungan Kerja (X2) dan variabel Kinerja Karyawan 
dikatakan valid, dimana $\mathrm{r}$ hitung $>\mathrm{r}$ tabel $(0,954)$. Sehingga semua pernyataan yang terdapat dalam variabel Karakteristik Individu (X1) variabel Lingkungan Kerja (X2) dan variabel Kinerja Karyawan (Y) dapat digunakan dalam peneliitian.

b. Uji Reliabilitas

\begin{tabular}{ccc}
\hline Variabel & $\begin{array}{c}\text { Chronbach } \\
\text { Alpha }\end{array}$ & Keterangan \\
\hline $\begin{array}{c}\text { Karakteristik } \\
\text { Individu }\end{array}$ & 852 & Reliable \\
$\begin{array}{c}\text { Lingkungan } \\
\text { Kerja }\end{array}$ & 729 & Reliable \\
Kinerja & 807 & Reliable \\
Karyawan & &
\end{tabular}

Sumber : Data Olahan 2019

Bedasarkan hasil pada tabel di atas dapat dilihat bahwa uji reliabilitas dalam perhitungan Chronbach Alpha untuk varibel X1 atau Karakteristik Individu mempunyai nilai sebesar 852 , variabel X2 atau Lingkungan Kerja mempunyai nilai sebesar 729 dan varibel $\mathrm{Y}$ atau Kinerja Karyawan mempunyai niali sebesar 807. Hasil pengujian reliabilitas dari variabel $\mathrm{X} 1, \mathrm{X} 2$ dan Y menunjukan bahwa masingmasing variabel memiliki nilai > 0,349 sehingga dapat dikatakan reliabel.

\section{Analisis Koefisiens Correlation Product Moment (R) dan Koefisiens Determinasi (R Square)}

Berdasarkan dari hasil analisis dengan menggunakan SPSS 23, maka diketahui nilai koefisien korelasi (R)
Sebesar 0,977. Pada tingkat koefisien determinasi atau ( $\mathrm{R}$ Square) mempunyai nilai sebesar 0.954 atau $95.40 \%$. angka tersebut dapat diartikan bahwa pengaruh antara Karakteristik Individu dan Lingkungan Kerja Terhadap Kinerja Karyawan.

\begin{tabular}{cc}
\hline Koefisien Korelasi & Tingkat Hubungan \\
\hline $0,00-0,199$ & Sangat Rendah \\
$0,20-0,399$ & Rendah \\
$0,40-0,599$ & Sedang \\
$0,60-0,699$ & Kuat \\
$0,80-1,000$ & Sangat Kuat
\end{tabular}

Sumber : Sugiyono 2014

\section{Uji Normalitas}

Uji normalitas bertujuan menguji sebuah model regresi, untuk melihat apakah variabel dependen memiliki distribusi normal atau tidak. Analisis statistik dilakukan agar dapat mengetahui normalitas data yang diuji dengan menggunakan distribusi Grafik $P-P$ Plot. P-P Plot menggunakan bantuan aplikasi SPSS versi 23:

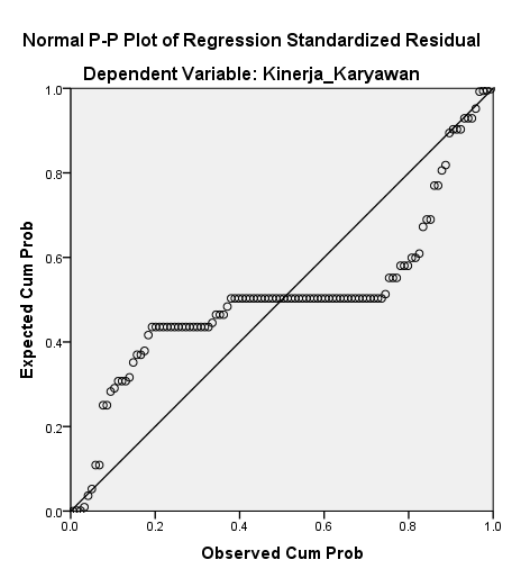

Berdasarkan Gambar diatas dapat dilihat bahwa data yang ada tersebar di 
sekitar garis diagonal dan mengikuti arah garis diagonal pada grafik histogram, hal ini menunjukkan bahwa terdapat pola distribusi normal. Jadi dapat disimpulkan bahwa dari Grafik P-P Plot, model regresi memenuhi asumsi normalitas.

\section{Uji Multikolinearitas}

Uji multikolinearitas digunakan untuk menguji ada tidaknya korelasi antar variabel independen. Karena model regresi yang baik ditunjukkan dari hasil uji tersebut. Agar dapat mengetahui ada tidaknya multikolinearitas dalam model regresi dapat diketahui dengan Tolerance Value (TOL) atau Variance Inflation Factor (VIF). Jika nilai TOL mendekati 1 atau besaran VIF kurang dari 10 maka model tidak terkena multikolinearitas.

Hasil perhitungan Tolerance menunjukkan bahwa variabel independen memiliki nilai Tolerance lebih dari 0,1 dengan nilai Tolerance variabel independen yaitu Karakteristik Individu sebesar 0,854, dan Lingkungan kerja sebesar 0,854. Sementara itu, hasil perhitungan nilai Variance Inflation Factor (VIF) dari variabel independen juga menunjukkan hal serupa yaitu tidak adanya nilai VIF lebih dari 10, di mana masing-masing rasio mempunyai nilai yaitu Karakteristik Individu sebesar 1.171 dan Lingkungan Kerja sebesar 1.171. Berdasarkan hasil perhitungan nilai
Tolerance dan VIF dapat disimpulkan bahwa tidak ada multikolinearitas antar variabel independen dalam model regresi.

\section{Uji Heteroskedastisitas}

Uji heterokedastisitas bertujuan untuk menguji adakah dalam model regresi terjadi ketidaksamaan variance dari residual pengamatan satu dengan pengamatan lainnya. Apabila variance yang dihasilkan residual pengamatan satu tetap disebut homoskedastisitas tetapi jika variance yang dihasilkan residual pengamatan satu berbeda, disebut heteroskedastisitas. Homoskedastisitas terjadi jika titik-titik hasil pengolahan data menyebar di bawah maupun di atas titik-titik origin (angka 0) pada sumbu $\mathrm{Y}$ dan tidak mempunyai pola yang tertentu. Heteroskedastisitas terjadi jika pada Scatterplot titik-titiknya mempunyai pola yang teratur, baik menyempit, melebar maupun bergelombang-gelombang.

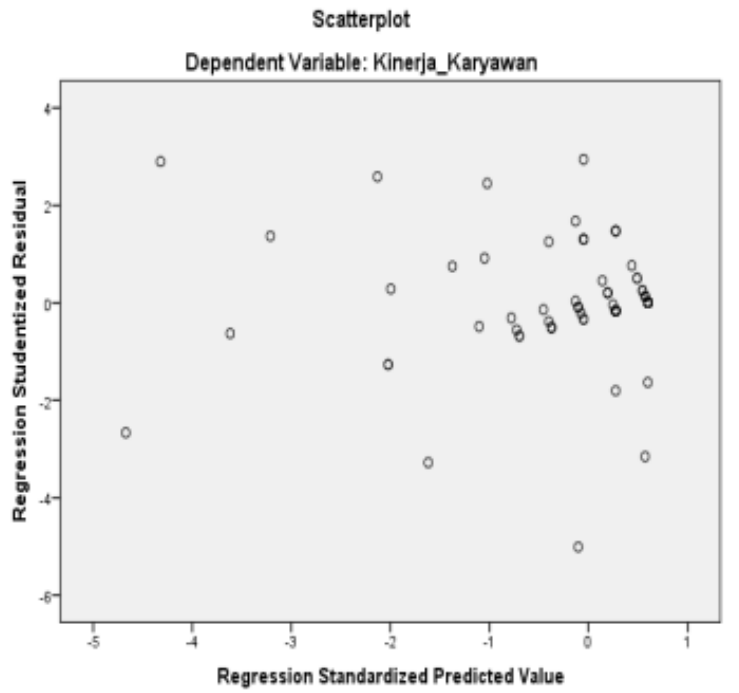


Berdasarkan Gambar diatas terlihat bahwa tidak ada pola yang yang jelas serta titik-titik tersebut menyebar di atas dan di bawah angka 0 pada sumbu Y. Hal ini menunjukkan bahwa dalam penelitian ini tidak terjadi heteroskedastisitas.

\section{Analisis Regresi Linear Berganda}

Diketahui persamaan regresi Bergand dalam penelitian ini yaitu sebagai berikut : $\mathrm{Y}=0.828+0.075+0.896+\mathrm{e}$ Berdasarkan hasil uji regresi linear sederhana di atas maka di ketahui nilai konstanta yaitu 0.828 dan koefisiensi regresi X1 yaitu 0.075, sehingga $\mathrm{X} 1$ berpengaruh positif. Pada variabel X2 sebesar 0.896 sehingga X2 berpengaruh positif terhadap variabel Y.

\section{Uji F}

Hasil analisis menghasilkan nilai Fhitung sebesar 1125.808 sementara F tabel sebesar 3.08 ini berarti nilai $\mathrm{F}$ hitung $>\mathrm{F}$ tabel, sehingga Ha diterima dan $\mathrm{HO}$ ditolak. Hal ini menjelaskan bahwa dalam penelitian ini variabel Karakteristik Individu dan Lingkungan Kerja secara bersama-sama/simultan berpengaruh signifikan terhadap variabel Kinerja Karyawan.

\section{Hasil dan Pembahasan}

Berdasarkan dari hasil penelitian diketahui bahwa semua pernyataan yang terdapat dalam variabel $\mathrm{X}, \mathrm{X} 2$ dan variabel $\mathrm{Y}$ dinyatakan valid karena nilai $\mathrm{r}$ hitung $>\mathrm{r}$ tabel $(0,308)$ Jika dilihat pada uji reliabilitas dalam perhitungan Chronbach Alpha untuk varibel $\mathrm{X} 1, \mathrm{X} 2$ mempunyai nilai sebesar 0,349 dan varibbel Y atau Kinerja Karyawan mempunyai niali sebesar 0,349 , maka hasil pengujian reliabilitas dari variabel $\mathrm{X} 1, \mathrm{X} 2$ dan $\mathrm{Y}$ menunjukan bahwa masing-masing variabel memiliki nilai $>0,05$ sehingga dapat dikatakan reliabel.

Dari hasil analisis data yang ada diketahui bahwa nilai koefisien determinasi (R Square) sebesar 0,954 sehingga dapat diartikan bahwa Karakteristik individu dan lingkungan kerja berpengaruh 95,40\% terhadap kinerja karyawan pada PT. Multi Nabati Sulawesi Bitung.

Koefisiensi regresi variabel $\mathrm{X} 1, \mathrm{X} 2$ sebesar 0,349 yang artinya bahwa setiap penambahan $1 \%$ maka nilai yang terdapat dalam Kinerja Karyawan juga bertambah sebesar 0,349.Koefisien regresi tersebut bernilai positif, sehingga dapat dikatakan bahwa arah pengaruh variabel $\mathrm{X} 1$ dan $\mathrm{X} 2$ terhadap variabel $\mathrm{Y}$ adalah positif.

Koefisien determinasi atau ( $\mathrm{R}$ Square) dalam penelitian ini yaitu sebesar 95,40\% sehingga dapat diartikan bahwa Karakteristik Individu dan Lingkungan Kerja memiliki pengaruh besar terhadap Kinerja Karyawan PT. Multi Nabati 
Sulawesi Bitung dan 4,60\% dipengaruh oleh faktor lain yang tidak diteliti.

Pembahasan dalam penelitian ini mengenai pengaruh Karakteristik Individu dan Lingkungan Kerja Terhadap Kinerja Karyawan PT. Multi Nabati Sulawesi Bitung Hasil Penelitian menunjukan Bahwa Variabel Bebas (Karakteristik Individu) dan (Lingkungan Kerja) merupakan variabel yang berhubungan terhadap variabel terikat (Kinerja Karyawan) Variabel Karakteristik Individu berpengaruh secara signifikan terhadap kinerja karyawan. Hal tersebut telah dibuktikan dengan pengujian hipotesis, baik melalui teknik analisis regresi berganda.

Diharapkan kepada perusahaan PT. Multi Nabati Sulawesi kiranya dapat terus meningkatkan Kinerja, sehinggah dapat memberikan kontribusi yang memuaskan bagi perusahaan.

\section{Kesimpulan}

Terdapat pengaruh antara variabel Karakteristik Individu (X1), variabel Lingkungan Kerja (X2) dan Kinerja Karyawan (Y) PT. Multi Nabati Sulawesi Bitung,jika dilihat dari tabel koefisien termasuk ke dalam golongan yang sangat besar pengaruhnya. Berdasarkan hasil dari analisis regresi linear berganda maka diperoleh nilai koefisien regresi yang positif, sehingga dapat dikatakan bahwa arah pengaruh variabel Karakteristik Individu dan Lingkungan Kerja terhadap variabel Kinerja Karyawan yaitu positif.

\section{Saran}

Setelah diperoleh pengaruh antara variabel Karakteristik Individu dan Lingkungan Kerja terhadap variabel Kinerja Karyawan pada PT.Multi Nabati Sulawesi yang sangat besar diharapkan peneliti selanjutnya akan meneliti tentang Kinerja Karyawan karena masih banyak faktor lain yang dapat mempengaruhi Kinerja Karyawan sehingga dapat digunakan sebagai dalah satu acuan dikemudian hari.

Diharapkan kepada perusahaan PT. Multi Nabati Sulawesi kiranya dapat terus meningkatkan Kinerja, sehinggah dapat memberikan kontribusi yang memuaskan bagi perusahaan.

\section{Daftar Pustaka}

Hernaus, Tomislav. 2014. Work characteristic and work performance knowledge workers. The Universitas of Newcastle Australia. Euromed Journal of Businnes. Vol 9 Iss 3 pp. 268-292.

Ratna Handayati. 2016. Pengaruh Karakteristik Individu Terhadap Kinerja Karyawan. Bantik Jatim Cabang Lamongan. Jurnal Katalogis, Vol.1, No-2.

Abdul Rahman, 2013. Pengaruh Karakteristik Individu, Motivasi dan 
Budaya Kerja Terhadap Kinerja Pegawai. Kabupaten Donggala. $e$ journal Katalogis, Volume 1 Nomor 2 hal 76-86.

Larasati, Sindi dan Aini Gilang. 2014. Pengaruh Motivasi Kerja Terhadap Kinerja Wilayah Telkom Jabar Barat Utara (Witel Bekasi). Jurnal Manajemen Organisasi Vol. V,No. 3, Desember 2014. Bandung: Universitas Telkom Bandung.

Rendi Mahardika. (2014). Pengaruh Karakteristik Individu dan Karakteristik Pekerjaan Terhadap Prestasi Kerja Karyawan (penelitian pada karyawan PT Inti Bara Mandiri Tuban).

JurnalAdministrasiBisnis.Vol. 12 1, Juni 2014: 1-5. Malang:Fakultas Ilmu Administrasi Bisnis, Universitas Brawijaya.

Rumawas, W. 2018. Manajemen SumberDaya Manusia.Universitas SamRatulangi (Unsrat Perss): Jln.Kampus Unsrat- Bahu Manado.

Saina, V. I. Pio, R. J. Rumawas, W. 2016.Pengaruh Worklife Balance dan Kompensasi Terhadap Kinerja Karyawan Pada PT.PLN (Persero) Wilayah Suluttenggo Area Manado. Jurnal Administrasi Bisnis Unsrat. Vol 4, No 3 (2016) 